\title{
A patient with primary sexual headache associated with hypnic headaches
}

\author{
Jesús Porta-Etessam • Irene García-Morales • \\ Daniella Di Capua · Rocío García-Cobos
}

Received: 14 November 2008/ Accepted: 14 December 2008/Published online: 10 January 2009

(C) Springer-Verlag 2008

\section{Dear Editor,}

We present the first report of association between primary sexual headache (PSH) and hypnic headache (HH).

A 36-year-old man without any relevant medical or headache history was referred to our Headache Clinic because of a 3-month history of headaches. They were of explosive onset, holocranial location, and exclusively triggered by sexual activity, and they lasted 5-30 min. At the time of consultation the patient had suffered more than 20 attacks. He also described another type of headache with episodes starting 1 month after the initial presentation of the orgasm-related headache. It was different in quality, dull, with bilateral location, moderate in intensity, awaking the patient, lasting for $3 \mathrm{~h}$. He had had more than 20 episodes per month occurring only during sleep. There were no other symptoms and the examination was normal. MRI and MR angiography of the head were normal. Indomethacin $25 \mathrm{mg} \mathrm{30-60} \mathrm{min} \mathrm{before} \mathrm{sleep} \mathrm{or} \mathrm{sexual} \mathrm{activity} \mathrm{was}$ started and decreased the headache intensity. A 50-mg dose was then prescribed, which resulted in resolution of headache.

Although this atypical association could be explained in terms of coincidence, $\mathrm{PSH}$ and $\mathrm{HH}$ are infrequent types of headache and could be the expression of a common pathophysiological mechanism. An impaired metabolic cerebrovascular autoregulation [1] was described as a causative factor in $\mathrm{PSH}$, and vasospasm was seen on angiography. On the other hand, $\mathrm{HH}$ has been related with an impairment of the suprachiasmatic nucleus and could cyclically activate a dysnociceptive mechanism leading to both sudden awakening and headache [2]. In any case, a common situational hypothalamic nucleus activation could induce disturbances of cerebrovascular autoregulation and a suprachiasmatic malfunction. Different studies on brain imaging show increased activation in the paraventricular nucleus of the hypothalamus during orgasm [3]. There are several cases providing evidence of the role of hypothalamus in the pathogenesis of vasospasm [4]. A hypothalamus malfunction could justify both types of headache, explaining the convergence of the two entities in our patient.

\section{References}

1. Evers S, Schmidt O, Frese A, Husstedt IW, Ringelstein EB (2003) The cerebral hemodynamics of headache associated with sexual activity. Pain 102:73-79

2. De Simone R, Marano E, Ranieri A, Bonavita V (2006) Hypnic headache: an update. Neurol Sci 27(Suppl 2):S144-S148

3. Argiolas A, Melis MR (2003) The neurophysiology of the sexual cycle. J Endocrinol Invest 26(Suppl 3):20-22

4. Hansen-Schwartz J (2004) Cerebral vasospasm: a consideration of the various cellular mechanisms involved in the pathophysiology. Neurocrit Care 1:235-246
J. Porta-Etessam $(\square) \cdot$ I. García-Morales .

D. D. Capua · R. García-Cobos

Headache and Neuroophthalmology Unit, Neurology

Department, Hospital Universitario Clínico San Carlos,

C/Andrés Torrejón, 15, 7º, 28014 Madrid, Spain

e-mail: jporta@yahoo.com 